\title{
Risibility research reviewed
}

\section{William H. Press}

WE TRY to keep it a secret, but we all know that research and teaching are not what science is all about. Rather those doubtless worthy activities are pale diversions from the real business of science, namely the invention, dissemination and elaboration of funny anecdotes about colleagues, parodies, doggerel and the occasional pithy aphorism or bon mot.

A Random Walk in Science, which was published about a decade ago as a collection of such fundamental material, has come to be held as a kind of urtext for all science, the ultimate peak of that pyramid which begins with primary publications at the bottom and then ascends to review articles, reviews of reviews and so on.

Now this sequel, collecting some 175 or so additional short pieces, can be added to that lofty edifice. Here, for everyone, there is something, whether whimsy like "The Use of Small Dogs in Physics Teaching" or broad jokes like the investigator who ate dehydrated food for 28 days and then gained $108 \mathrm{lbs}$ in ten minutes while caught in a rainstorm. Parody ranges from the predictably amusing "I am the very model of ...", to the arcane, such as Shelley's Ozymandias ("Two vast and trunkless legs of stone/Stand in the desert . . . Look on my works, ye Mighty, and despair!. . .") rewritten as the geology paper "Twin Limb-like Basalt Columns and Their Relationship to Plate Tectonics".

Scientists cannot resist applying scientific observation to their own endeavours, yielding, for example, a description of their university hierarchy, from the Dean who leaps tall buildings in a single bound, through Professor (leaps short buildings with a running start and favourable winds),

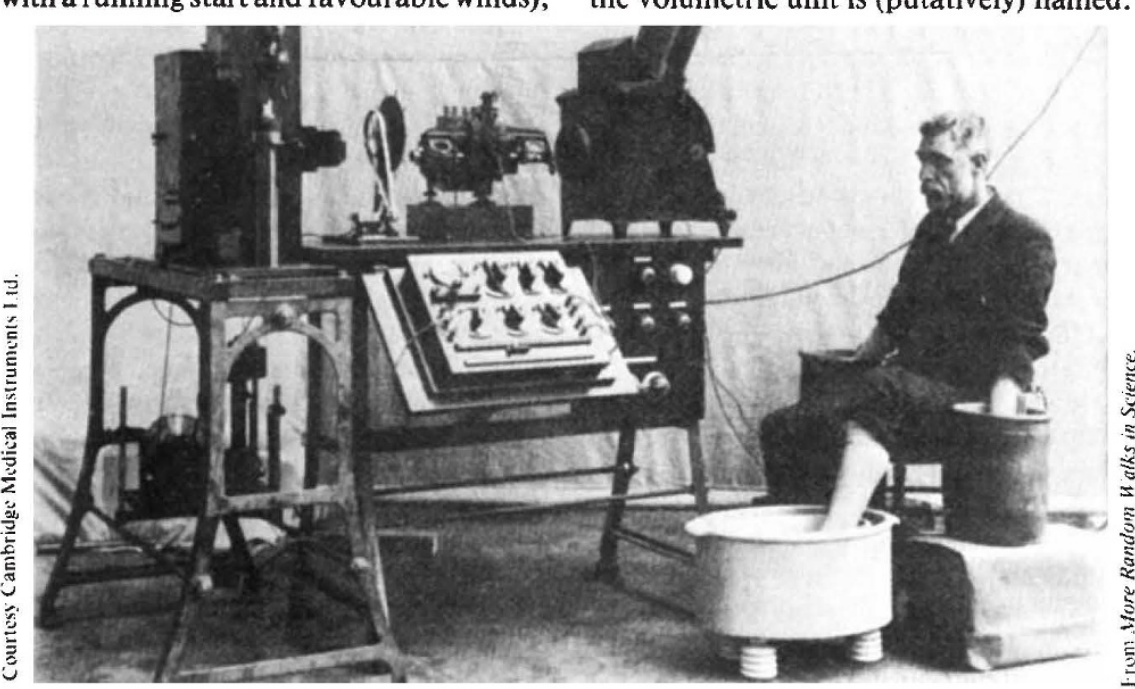

Having fun in the laboratory? This doleful character appears to have doubts about the safety of the original electrocardiograph (c. 1911).
More Random Walks in Science. Compiled by Robert L. Weber. Pp.207. ISBN 0-85498-040-7. (The Institute of Physics/ Heyden: 1982.) £9.95, \$19.50.

graduate student (runs into buildings) and finally department secretary (lifts buildings and walks under them). There is also a piece which rings true on the various types of obstructionists on committees and panels, and another on the "game" of refereeing. (The author's goal is to publish a worthless paper; the referee's is to have a major contribution to the field refused.

"No matter what degree of rigor the author uses, the referee replies by saying that it is not the correct one."').

Anecdotes are nicely represented. We have the famous theoretician Sir Harold Jeffreys, consultant to an oil company, listening attentively to a full day's presentation and then offering his (oniy) advice: "I'm glad it's your problem and not mine". We have Bessel receiving from King Friedrich Wilhelm not the needed funds to improve his observatory, but rather a medal for having attained such excellent results with primitive equipment. We have Pauli in heaven, hearing with mounting impatience God's explanation of the protonelectron mass ratio and finally snapping back, "Wrong!'. And Rutherford's memorable encounter in a glass-teapot works.

Literary hoax is represented by the paper coauthored by a cat (so that the sole human author could use the word "we" over an editor's objections), and by the biography of Claude Litre, the celebrated eighteenthcentury maker of wine bottles after whom the volumetric unit is (putatively) named.
The volume also contains perhaps the finest scientific biography of Sir William Rowan Hamilton ever penned, here quoted in its entirety:

\section{Higgledy, piggledy \\ William R. Hamilton \\ Wrote on mechanics, in- \\ Frequently joked, \\ Wrote on quaternions, \\ Tackled intractable \\ Hydrodynamical \\ Problems, and croaked.}

While perhaps unsuitable as an introductory text, this volume will certainly fill the needs of advanced students and practitioners in the field.

William H. Press is Professor of Astronomy and Physics, and Chairman of the Department of Astronomy, at Harvard University.

\section{How to be a scientist}

\section{Walter Gratzer}

Winning the Games Scientists Play. By Carl J. Sindermann. Pp.285. ISBN 0-306-41075-3. (Plenum: 1982.) \$15.95, $£ 10.05$.

WE ALL agree that there is more to science than doing research. The politics of professions in which scope for the exercise of power is limited or illusory, such as the academic or the ecclesiastical, tend to be conducted with particular ferocity and vindictiveness, redeemed only by the incompetence of most of the protagonists. It is a subject that invites satirical dissection: someone should do for our profession what A.P. Herbert did for (or to) the law.

I picked up Dr Sindermann's book with eager anticipation. The title is full of promise and from the dust-jacket the author, wearing a natty check and the suggestion of a knowing smile, looks at one appraisingly with gimlet eyes - clearly A Man that Waiters Spring to Serve. I averted my gaze and turned to page 1 . But what was this? The first sentence averred that the book had been written for "thousands of serious dedicated scientists", such as myself, "to ensure that they [may] participate fully and joyously in a genuinely wonderful occupation". If this was a manual of gamesmanship for the 